\title{
When fashion meets crowdfunding: exploring sustainable and innovative features of online campaigns
}

\author{
Carolina Dalla Chiesa, Alina Pavlova, Mariangela Lavanga and \\ Nadiya Pysana \\ Erasmus Universiteit Rotterdam, Rotterdam, Netherlands
}

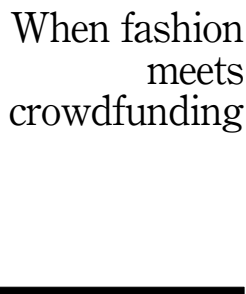

Received 23 March 2021 Revised 11 September 2021 9 December 2021

Accepted 30 January 2022

\begin{abstract}
Purpose - This paper analyses the factors that make fashion-product crowdfunding campaigns successful. The authors argue that crowdfunding is an innovative and functional way of bringing new fashion items to the market. The purpose of this paper is to answer the question whether product innovation, lifecycle and sustainability have a positive effect on the success of fashion crowdfunding campaigns. The findings highlight that the success of the fashion crowdfunding campaigns depends on creators' adherence to the values of the platform which they use to raise capital.

Design/methodology/approach - A total of 300 fashion crowdfunding projects running between the 17 th of October and the 15th of December 2017 were collected from Kickstarter - the world's largest crowdfunding platform based on reward-based all-or-nothing model. Two-step binomial logistic regression was used to analyse the data.

Findings - The model predicted a significant increase in the odds of success for the fashion items crowdfunded during the first-time production, and innovative and environmentally sustainable products with a higher price range of rewards. In line with previous literature, regression analyses predicted a significant effect of the control variables of goal amount (negative) and the number of rewards (positive). Contrary to previous studies, neither the presence of a video nor the campaign length predicted success.

Originality/value - The novel findings of this study contribute to the literature by providing an analysis of success factors of fashion items on crowdfunding platforms. The results show that innovative, environmentally sustainable and higher-priced products produced by early-stage ventures are better welcomed by the audiences.
\end{abstract}

Keywords Fashion, Crowdfunding, Success factors, Innovation, Kickstarter

Paper type Research paper

\section{Introduction}

Crowdfunding is an emerging way of financing creative projects (Mollick and Robb, 2016; Sorenson et al., 2016). It has primarily evolved from cultural sectors to other areas such as design, technology and non-creative areas (Dalla Chiesa and Handke, 2020). The literature on crowdfunding has extensively explored the characteristics of campaigns under the framework of signalling theory applied to success-factor analyses (Butticè and Unghetto, 2021; Shneor and Vik, 2020; Cumming and Hornuf, 2018). It has not, however, explored extensively sector-specific realities, with much work still required as noted by Short et al.

(C) Carolina Dalla Chiesa, Alina Pavlova, Mariangela Lavanga and Nadiya Pysana. Published by Emerald Publishing Limited. This article is published under the Creative Commons Attribution (CC BY 4.0) licence. Anyone may reproduce, distribute, translate and create derivative works of this article (for both commercial and non-commercial purposes), subject to full attribution to the original publication and authors. The full terms of this licence may be seen at http://creativecommons.org/licences/by/4.0/ legalcode

Funding: No funding has been received for the purpose of this study.

Conflicts of interest/Competing interests: No potential conflict of interest was reported by the authors.

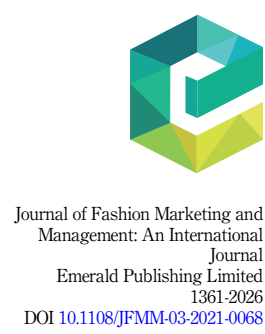

Journal of Fashion Marketing and Management: An International 1361-2026 DOI 10.1108/JFMM-03-2021-0068 
(2017). It is well known that certain sectors reach better funding success rates than others on crowdfunding platforms. Typical product features affect the results of campaigns (Wehnert et al., 2019) and, as Kickstarter (2021) show, cultural campaigns (e.g. dance, theatre, music and visual arts) often achieve higher success rates, whereas fashion [1], technology and design are normally less successful, possibly due to more expressive campaign goals and different economic features of more tangible creative products.

Crowdfunding has been celebrated as a powerful funding tool for the emergent, earlystage career, do-it-yourself initiatives that otherwise struggle to access funding opportunities (Mollick and Robb, 2016; Leboeuf and Schwienbacher, 2008). Particularly, before taking on substantial financial commitments, entrepreneurs can test audiences' perceptions of a product and mitigate the risks associated with unknown demand (Hoffman and Lecamp, 2015). The audience testing aspect is particularly helpful for the creative industries where an infinite variety of projects and information asymmetry make it difficult to fully predict demand patterns (Kretschmer et al., 1999; Caves, 2000). In the case of fashion goods, uncertainty may be amplified by the complexity and geographical span of the supply chain and high upfront production costs (Wubs et al., 2020a), hence crowdfunding market testing is especially beneficial.

Fashion is one of the most innovative creative industries (Raustiala and Springman, 2006; Lavanga, 2018) and also a domain where luxury and high prices coexist with low prices and scalability (Lavanga, 2018). It is a sector in which oversupply of (new) products and high demand uncertainty dominate (Pratt et al., 2012; Brydges, 2018; Lavanga, 2018). While entering the industry is easy, most companies struggle to remain in business (Jacobs et al., 2016). Fashion entrepreneurs face proportionally higher risks than other sectors in the arts due to the high sunk costs involved with starting a fashion company and remaining in business. That is the reason why crowdfunding can be seen as an interesting strategy for testing the acceptance of products to reduce risks of failure (Viotto-da-Cruz, 2018; Belleflamme et al., 2014).

Fashion is also one of the most polluting industries globally, although concern about its environmentally unfriendly practices (Todeschini et al., 2017; Beard, 2008) has now given rise to more sustainable alternatives than the globalised mass production that has been the dominant in recent years (Clark, 2008; Fletcher, 2012; Brydges et al., 2014, 2018; Leslie et al., 2014; Brydges, 2018; Lavanga, 2019; Gwilt et al., 2019). Additionally, mass fashion manufacturing has been characterised by unfair and unsafe working conditions (Crewe, 2013; Reinach, 2005) while sustainable initiatives are mostly the work of independent, emerging designers. The smaller players that produce more durable merchandise (Chapman, 2015) have to compete in the market with established firms (Janssens and Lavanga, 2020). The question arises whether innovative and sustainable new fashion players would enjoy higher success rates on crowdfunding platforms.

In order to evaluate the extent to which early-stage products, innovative ventures and sustainability-based campaigns yield successful results on multi-purposes crowdfunding platforms such as Kickstarter, this article delves into features of fashion crowdfunding campaigns. The research question is as follows: "What features of fashion crowdfunding projects predict the successful funding?" To answer this question, we examined a sample of 300 projects extracted from the Kickstarter platform by using logistic regression. To the best of our knowledge, this is the first comprehensive study on success factors for fashion campaigns on crowdfunding platforms. The remainder of the paper is structured as follows: Section 2 reviews and brings together the literature on crowdfunding in general, and fashion crowdfunding, as well as provides support for the hypotheses tested in this study; Section 3 describes the methods used and the data collection; Section 4 presents the descriptive statistics and regression results; Section 5 is dedicated to the discussion; and Section 6 comprises the conclusion. Our study suggests that higher priced environmental-friendly 
fashion products with innovative features that are initiated by early-stage ventures yield significantly higher success rates on crowdfunding platforms.

\section{Literature review}

\subsection{The rise of crowdfunding and the importance of signals}

In recent years with the help of digitalisation new online financing models like crowdfunding are being used to address the funding gap experienced by early-stage entrepreneurs (Cumming and Hornuff, 2018). Crowdfunding emerged early in the year 2000 as an innovative way for entrepreneurs to use "the crowd" to support creative projects and introduce new goods to a market where access to funds may have been restricted to agents (Dalla Chiesa and Handke, 2020). Crowdfunding is thus considered to be one of the most important financial innovations due to the novel way it enables entrepreneurs to obtain funds that would be unavailable to them through more traditional methods (Kuti and Madarasz, 2014). Up to this point, the creative industries have largely used the reward-based platforms (Dalla Chiesa and Handke, 2020), and so does fashion sub-sector. One of the most well-known platforms is Kickstarter [2] (Mollick, 2014), which we used for our analysis. Since its inception, as much as four billion USD have been pledged to various creative projects, funding more than 155,000 of them. Around 161 million USD have been pledged to fashion campaigns (Kickstarter, 2021), which form the empirical focus of our study.

Extensive research has been conducted on the success factors of campaign signals (Butticè and Unghetto, 2021; Shneor and Vik, 2020; Cumming and Hornuf, 2018; Vismara, 2018, Short et al., 2017) as these are ways of reducing information asymmetry intrinsic to market exchange (Akerlof, 1970) and selecting between low and high quality products (Kirmani and Rao, 2000). Due to the high information asymmetry present in online funding behaviour creators have limited ways to signal quality of their products and, therefore, rely on the veracity of product description narratives. Typically, credibility signals including campaign descriptions, media, goal, price, the range of rewards and language have been widely discussed (Manning and Bejarano, 2017; Courtney et al., 2016; Mollick, 2014). Little attention has been given to innovativeness and sustainability aspects. External campaign features such as geographical distance (Mendes Da Silva et al., 2016), gender (Gorbatai and Nelson, 2015) and social capital (Colombo et al., 2015) also have an impact on success.

In line with value signalling research, we draw on the campaigns and products features as presented by the creators. Specifically, our analysis focuses on such potential predictors of success as signalling sustainability, stage of venture development and innovativeness in a fashion sector-specific context.

\subsection{Crowdfunding the initial stages of fashion project}

Reward-based crowdfunding projects available on Kickstarter are typically created by firms or ventures in the initial stage, wanting to pre-finance their production phase and test product acceptance (Gafni et al., 2019). If a considerable number of people are involved in this stage, the entrepreneur will achieve important goals: market validation, acquisition of funds to finance their activities and gathering of information (Viotto da Cruz, 2018). As Lee et al. (2015) highlighted, crowdfunding enables small new organisations to access capital during hard financial times. When established companies dominate, there is little opportunity, and almost no room for start-ups to evolve due to both a lack of funding options and a high risk associated with investing in early-stage ventures (Belleflamme et al., 2014). Therefore, crowdfunding is a solution for fledgling firms and emerging businesses looking to finance their projects. As well as providing entrepreneurs with access to financial resources, crowdfunding also provides them with an opportunity to interact with a broader audience
When fashion meets crowdfunding 
(Stanko and Henard, 2016) where these audiences can also express their opinions, pre-order products or request specific features of the products (Gerber and Hui, 2016). As Dickinson (2011) observed, the development of a firm can be described by recurring to different stages of its lifecycle. This theory is commonly associated with the lifecycle of start-ups in the crowdfunding literature (Paschen, 2017) [3] as, typically, start-ups need easier and more rapid access to funds due to the constraints faced in traditional funding options. In crowdfunding schemes, evidence has shown that entrepreneurs choose this route in early stages of product development (Lasrado, 2013).

When applied to the case of fashion products, extensive literature shows that the lifecycle of such goods is short and characterised by induced obsolescence (Sproles, 1974, 1981; Andreozzi and Bianchi, 2007; Raustiala and Sprigman, 2006; Aspers and Godart, 2013; Janssens and Lavanga, 2020). Big fashion companies produce between two and 20 collections a year, with new products flocking to stores every five weeks (examples are fast-fashion firms like H\&M and Zara). To deliver innovative and well-timed products at a rapid pace and compete with fast-fashion giants, smaller fashion entrepreneurs/designers require most of their finances to be in place in the early stages of their supply chain, where products are designed, samples are made, textiles and other materials (e.g. leather) are sourced and manufacturers are contracted.

Timing is decisive in managing fashion production when the market is characterised by "short lifecycles", "high volatility", "low predictability", and "high impulse purchasing" (Christopher et al., 2004, p. 367). For the reasons listed above, we argue that fashion projects will attract most crowdfunding capital in this early stage (design, sampling and production), rather than in later stages (distribution or expansion). Additionally, backers often extend their support towards early-stage projects as an act of altruism or belief in ideas that otherwise would face major obstacles to reach sufficient funds (Gerber and Hui, 2016; Dalla Chiesa, 2021). We contend that crowdfunding projects will better benefit from this model when relating to exclusive perks in the early stages of production - inception, creation, prototyping and distribution - rather than in later stages. Moreover, advanced projects with sufficient prior success may face backlash from the public as the need for crowdfunding support is diminished (Watercutter, 2013). We, thus, predict that projects in initial production stages will benefit from higher chances of success.

H1. There is a positive association between fundraising success via crowdfunding and the lifecycle of the fashion project.

\subsection{Crowdfunding innovative fashion products}

In addition to early-stage financing, crowdfunding has been welcomed as a financial tool helping to bring the most innovative ideas to the market (Chan and Parhankangas, 2017; Downes, 2013). According to Fagerberg (2004), the interest in innovation is sparked not only because of the importance technological breakthroughs but also as a result of social and economic importance. According to the theory of social signalling people often make choices, including buying decisions, to 1) try to identify with each other (Kuppuswamy and Bayus, 2015; Gerber and Hui, 2016; Agrawal et al., 2015); 2) seek recognition (Bretschneider et al., 2014); or 3) seek to be part of a community or co-creation (Ordanini et al., 2011; Hobbs et al., 2016; Gerber and Hui, 2016). Hence, we posit that social signalling will drive crowdfunding backers to show preference to innovative fashion projects. In fact, we know that in fashion crowdfunding, projects of higher complexity and craftsmanship are more likely to be valued and, hence, funded (Dey et al., 2017). However, while innovation is easy to define for some crowdfunding categories (e.g. technology, design), it is harder to do so in fashion products, amongst other creative and cultural goods. 
New fashion products are usually seen "as styles [of sartorial details that contribute to overall appearance] and as fads that are particular changes in the components of dress" (Crane, 1997, p. 16). Robinson (1958, p. 127) contended that fashion is the "pursuit of novelty for its own sake" and that innovation entails "change in the design of things for decorative purposes" (Robinson, 1961, p. 376). In contrast to the position with flocking, Hemphill and Suk (2009, p. 199) argued that differentiation, meaning "to reinterpret, change, remix, and transform, and as such resist the sheer replication of existing works even while incorporating them", could characterise innovation in fashion. Fashion products are developed with both familiarity and novelty (Andreozzi and Bianchi, 2007; Czarniawska, 2011), regardless of whether this results from with the revival of old designs and styles or the introduction of new features and/or changes made to existing ones (Kretschmer et al., 1999).

In other words, fashion innovation seems to greatly circumvent a technological change used in the modification of product designs and creation of new markets for innovative garments (Abernathy and Clark, 1985). Given the centrality of fashion innovation in garment pieces or accessories, scholars tend to consider these changes incremental and cumulative (Santagata, 2004) whereby copying and remixing of existing designs allows for the development of new products continuously (Hemphill and Suk, 2009). Innovation in fashion is thus mostly directed at incremental changes of existing products, such as by adding embellishments and altering colours and fabrics. At the same time, some fashion innovation can be considered more radical and disruptive. Especially, when new products entail a paradigm shift (Tidd et al., 2011). Consider, for example, new design features such as a coat with a temperature control, an object being sewn from a material produced by using different technology (e.g. leather derived from mushrooms (Anzilotti, 2018)) or even more functional innovation such as adding an extra accessory that is useful, but which nobody expects.

Notably, we argue that incremental innovation in fashion is often based on a subjective meaning-making and, thereby, is difficult to judge. At the same time, more radical functional innovation is usually signalled by a narrative description and, hence, is easier to interpret and take into account in one's backing decision. Typically, backers assess the innovative qualities of crowdfunding ventures on the basis of text narratives, images, videos and other credibility cues such as reviews and interaction with potential supporters (Butticè and Unghetto, 2021; Mollick, 2014; Stanko and Henard, 2016). Consequently, we argue that the backers will more likely to fund the fashion crowdfunding projects that signal functional innovation.

H2. There is a positive association between successful fundraising via crowdfunding and the innovative features of a fashion product.

\subsection{Crowdfunding environmentally and socially sustainable products}

Sustainability is arguably one of the most important parts of international agenda today. According to 2030 Sustainable Development Goals, in addition to environmental and social aspects of sustainability, societies should strive towards a more sustainable economy (SDG, 2021). Crowdfunding as an alternative source of financing might contribute to this sustainable agenda, especially if we learn that the projects that enjoy crowdfunding success are likewise more sustainable. In other words, when it comes to economic exchanges, sustainability takes the form of goods and services that these exchanges produce (Robertson, 2021). Entrepreneurial ventures are increasingly striving towards achieving sustainability and accessibility to consumers of various regions and social strata. Hence, it is possible that new financing models, such as crowdfunding, are supporting more sustainability-oriented entrepreneurs (Calic and Mosakowski, 2016). As sustainability becomes increasingly important, it is essential for fashion creators, designers and creative entrepreneurs to engage with it (Calic and Mosakowski, 2016). Schwienbacher and Larralde (2010) also maintain that financial incentives might not be as 
important for supporters as intrinsic motivations resulting from the wish to see a good project thrive, especially when a greater benefit is promised (Gerber and Hui, 2016).

The production phase of garments has received a lot of criticism as one of the most polluting industries in the world, due to its excessive use of water, pesticides, chemicals and energy during the different phases of its supply chain; and the mountains of landfill created when a products lifecycle has come to an end. The entire industry is invested in increasing its flexibility in terms of design, delivery and speed getting to the market (Christopher et al., 2004; Bhardwaj and Fairhurst, 2010). This is a practice that has led to consumers buying new and low-cost garments weekly, or even daily, and then disposing of them more often (Beard, 2008; Leslie et al., 2014; Brydges, 2018). In addition, unfair and unsafe working conditions (i.e. child labour, low wages, long working hours and health and safety issues) dominate fashion manufacturing. Accessible and affordable clothing has been made possible due to the lowcost of offshore production, which is contracted out to bidders with the lowest costs and in countries with lax environmental and work protections (Brydges, 2018; Crewe, 2013; Reinach, 2005).

These adverse environmental and social effects have triggered a shift towards a more sustainable approach to fashion. This is driven by small and independent brands as an alternative to the world of fast fashion and globalised mass production, although the approach is now being embraced by larger conglomerates (Fletcher, 2012; Fletcher and Grose, 2012; Brydges, 2018; Leslie et al., 2014). Environmental sustainability (ES) involves the reduction of waste and pollution through the efficient use of natural resources, recycling or reusing products or the adoption of a circular economic model (Todeschini et al., 2017). Social sustainability, meanwhile, refers to companies improving working conditions for their employees. Following the Rana Plaza collapse in Bangladesh in 2013, a fashion revolution was initiated to push consumers to adopt more sustainable fashion practices and demand greater transparency and control over the entire supply chain [4]. Within crowdfunding literature, sustainability (social and environmental) is not predominant in the empirical analyses, but it has gauged more attention recently (Motylska- Kuzma, 2018; Wehnert et al., 2019; Mæhle, 2020). A few empirical studies show how projects with sustainable characteristics are more successful (Calic and Mosakowski, 2016) and often develop better messages in their campaign (Mæhle, 2020). However, in equity crowdfunding, this finding is not confirmed (Vismara, 2019). Whilst sustainability is relevant [5] for all four crowdfunding models, loan-based projects seem to have the highest success rates in relation to sustainability [6] (Mæhle, 2020). We, thus, hypothesise that ES and social sustainability (SS) is also important for the success of fashion crowdfunding calls given the pressure this sector faces for more responsible production processes.

H3. There is a positive association between fundraising success via crowdfunding and the sustainability characteristics of a fashion product:

$H 3 a$. There is a positive association between fundraising success via crowdfunding and the ES characteristics of a fashion product.

$H 3 b$. There is a positive association between fundraising success via crowdfunding and the SS characteristics of a fashion product.

\subsection{Crowdfunding high-value products: price effect}

Even though fashion market is widely populated with scalable and low-price items, fashion products have been historically associated with luxury (Maza, 2006). In economic terms, luxury items are price-inelastic or even have positive price elasticity, i.e. they are purchased relatively more when prices rise. They can also be regarded as goods subject to conspicuous consumption (Veblen and Chase, 1934), where they are a signifier of status, prestige and 
distinction (i.e. "Veblen goods"). A luxury product must put quality before quantity and adopt aesthetics before functionality (Kapferer and Bastien, 2012). Another sign of luxury is scarcity and exclusivity (Kapferer and Bastien, 2012), with luxury brands actively using the former for marketing purposes and to satisfy the demand from consumers for the latter (Park et al., 2008). Such brands sell exclusive products as a way for consumers to distinguish themselves from others (Brydges, 2018; Lavanga, 2018). In this way, both prestige and individuality are closely related to the perceived scarcity of products.

Within crowdfunding, price is displayed in two forms: the target goal (i.e. the necessary payment for the project to take-off), and the various rewards (i.e. the products offered to potential supporters that together will add up to the target goal). Usually, when supporters pre-buy a crowdfunding project within the AON (all-or-nothing) reward-based method, their monetary contribution is given in exchange for a reward. As such, the reward in crowdfunding is the best proxy for price for which product is under offer within this online funding scheme. Other than the central product (e.g. a piece of garment, a video game, a music album, etc.), creators also offer ancillary products that may exert warm glow benefits or intrinsic motivation in backers (Andreoni, 1990; Frey, 1994). Altogether, these rewards combined form all the various products offered by founder who expects to reach the maximum consumer surplus possible by offering a range of various products/rewards with various prices (Dalla Chiesa and Handke, 2020). Ultimately, the average price of all reward items represents the price of that campaign (i.e. what the founder stipulated to be able to reach the target goal via pre-selling products).

The crowdfunding literature describes how projects often offer low-price rewards and lower goals that lead to more successful cases (Mollick, 2014). Given that fashion has several approximations with luxury, we hypothesise that a "low-price, low-goal" combination will not be present in fashion. Hence, this sector demonstrates peculiarities that sets it apart from other areas. As crowdfunding websites are populated with independent designers and smallscale entrepreneurs, large retailers are not present, which tends to increase the price of products due to an initial low level of scalability. For these reasons it is logical to assume that higher average price of the fashion crowdfunding rewards should be more desirable by the backers [7].

H5. There is a positive association between fundraising success via crowdfunding and the price of a fashion product.

\section{Data collection and methods}

We used Kickstarter, the world's largest crowdfunding platform and a reward-based all-ornothing model, to analyse the factors contributing to the success of fashion-related crowdfunding projects. We were able to identify 300 fashion projects that were running between the 17th of October and the 15th of December 2017 [8]. We did this using the Winautomation software, in which a piece of code is developed to navigate through a website to collect the HTML source codes of each projects hyperlink. Of these 300 projects, only 282 were relevant, as 17 projects were cancelled by the founder (regardless whether they have reached the goal), and for one project the campaign was hidden for retrospective viewing by the founder. We relied on Kickstarter labels to identify fashion as a category and collected the following campaign information: text; campaign goal; amount pledged (paid by backers); campaign duration; number of rewards; price of each reward; number of updates; number of comments; founder's country; and fashion category. We also manually assessed if the campaign has a video or not, as these are signs of credibility in crowdfunding campaigns (Mollick, 2014). Furthermore, from prices of individual rewards per campaign we calculated the average price of reward. As some of our covariates were latent variables, we manually 
coded them from the campaign text. These variables were - lifecycle, signalling of social sustainability, signalling of ES and innovativeness. Intercoder reliability for the latent variables was high (Cohen's Kappa above 95\% [9]), indicating good agreement and accuracy in the coding, hence robustness of the concepts.

We used binomial logistic regression to analyse the data. This method fit both our data (binary success/failure dependent variable and several binary independent variables). The logistic regression approach has also been widely used and is a method of choice in earlier research reported in the literature on crowdfunding success (Mollick, 2014; Beier and Wagner, 2015). The 2-step regression was performed where Step 1 only included the control variables, and Step 2 used a forced-entry regression method, meaning that all the predictors and controls were forced into the model simultaneously (Field, 2013). We used glm command of rstats package in $R$ ( $\mathrm{R}$ Core Team, 2013).

\subsection{Operationalisation of the variables}

In this analysis, the dependent variable is a binary indication of either the success or failure of a crowdfunding campaign. As Kickstarter projects are based on the all-or-nothing (AON) funding model, a campaign was deemed to be successful if the amount raised was equal to or higher than the sum sought, and unsuccessful if this amount was lower than the sum requested. We coded the successful and unsuccessful campaigns as 1 and 0 , respectively. The predictor variables are lifecycle, innovativeness, sustainability and price. Firstly, we coded lifecycle according to the stage of production that a campaigns product represented. We defined two such stages: first-time production and expansion. By first-time production, we mean that a product (1) has not been sold/market-tested (samples) commercially before being described in the text of a campaign, (2) is not a part of an established brand. Expansion means that the product is a part of an existing brand/line, or the product has already been market tested and the campaign is intended for continuous production or to present a new version of the product. In other words, the goal of an expansion campaign is to scale up the initial production or sell an incrementally improved version of an already existing and successful item (i.e. new features added, improved "2.0" version). Sometimes fashion campaigns are also intended to roll-out a brand. If this is the case, the brand should be new, and not present an expansion of the already existent business. We coded first-time production as 0 and expansion as 1 .

We coded innovativeness as a dummy variable. As described in the literature review, a fashion crowdfunding product was considered to be innovative if it presented backers with functional innovation features. Whether the product is innovative or not, was decided based on the presence of either of: (1) the product is made from new innovative material, (2) the product has new functionality unrelated to its aesthetic appearance. Additionally, we looked at ES and SS. Although we did not have the means to check if an item was truly sustainable, we did not distinguish products by the quality of the campaign's sustainability description; instead, we examined whether the sustainability discourse or, in economic terms, sustainability signalling, had an effect on success when products were described as sustainable more frequently.

We coded SS as 1 if at least one of these conditions was met by the campaign or product description: a) mentioning the use of fair trade components, b) mentioning responsible labour practices (no child labour, slave labour, mostly if the sourcing or production is done in developing countries), c) mentioning the contribution to the local community, volunteering practices or the use of funds collected from sales for charitable purposes and d) explicitly mentioning that the product is "socially sustainable" or "community friendly". We coded ES of the product 1 if at least one of these conditions was met by the campaign or product description: a) mentioning that the product was made from organically produced or recycled materials, b) mentioning that the production is not water-intensive and c) explicitly 
mentioning that the product is "environmentally sustainable" or "environmentally friendly". As for price $(\mathrm{P})$, we coded price as the average price of the rewards offered by campaign founders to potential backers. So, if a campaign offered ten rewards of different prices, these were added together and divided by 10 .

\subsection{Control variables}

Firstly, the financial goal was controlled for as a factor that has a negative effect and is, relatively speaking, both beyond the campaign founder's control and a significant predictor of crowdfunding success (Mollick, 2014; Hobbs et al., 2016; Beier and Wagner, 2015). Secondly, by the scarcity principle, campaign duration has also been found to have a significant adverse effect on the success of a crowdfunding campaign (Mollick, 2014; Beier and Wagner, 2015; Hobbs et al., 2016). This principle concerns the tendency to assign a higher value to items that are available in limited numbers or those that are only available for a limited time. Campaign duration was measured in this study as how long, in days, a campaign was set to last. We also controlled for number or rewards, which is a vital variable in several studies. According to Mollick (2014), the number of rewards affects crowdfunding success positively in terms of each backer's willingness to pay, as there are more options available to do so (Sharp et al., 2014). Lastly, we included "video" as a control variable, given that it provides minimum standards to campaigns. According to Mollick (2014), videos can signal some minimal quality. We have coded 1 if the campaign had a video and 0 if it had not.

\subsection{Assumption checks}

The variables "Goal", "Number of Rewards", and "Price" were subject to outliers (assessed via Tukey fences) (Tukey, 1977). Since outliers could have affected the regression results by creating associations that do not exist, we have solved the problem of outliers by $1 n$ transforming these variables. Additionally, the "Number of Rewards" variable was capped to 5 th and 95th percentiles because the ln-transformation did not wholly solve the outliers (see winsorizing technique in Field, 2013). The model assumptions were met, with no multicollinearity detected between the variables (VIFs $<3$ ) (Bowerman and O'Connell, 1990; Myers, 1990), no over-dispersion [two degrees of freedom ratio of $\chi 2$ test $<2$ (Field, $2013)]$ and the linearity of the logit assumption met for all the predictor variables $(\phi>0.05)$. The sample size of 282 was adequate to fit predictors (5) and controls (4) without overfitting the model (Peduzzi et al., 1996).

\subsection{Model}

$$
\begin{aligned}
\text { Ln }= & \rho \frac{(\text { SUCCESS })}{1-\rho(\text { SUCCEESS })}=\beta_{0}+\beta_{1} \text { Lifecycle }_{i}+\beta_{2} \text { LN_Price }_{i}+\beta_{3 a} \text { SE }_{i}+\beta_{3 b} S S_{i} \\
& +\beta_{4} \text { Innovativeness }_{i}+\beta_{c 1} L N_{-} \text {GoalEUR } \\
& +\beta_{c 2} \text { CampaignDuration }_{i} \\
& +\beta_{c 3} \text { LN }_{\text {Number }} \text { of Rewards }(\text { capped })_{i}+\beta_{c 5} \text { Video }_{i}+\varepsilon_{i}
\end{aligned}
$$

\section{Results}

\subsection{Descriptive statistics}

The majority of the projects examined originated in the United States, followed by Western Europe, the United Kingdom and Canada. There were also founders located in Europe, South America and Asia. Interestingly, it was Europe, in particular Northern, Eastern and Western 


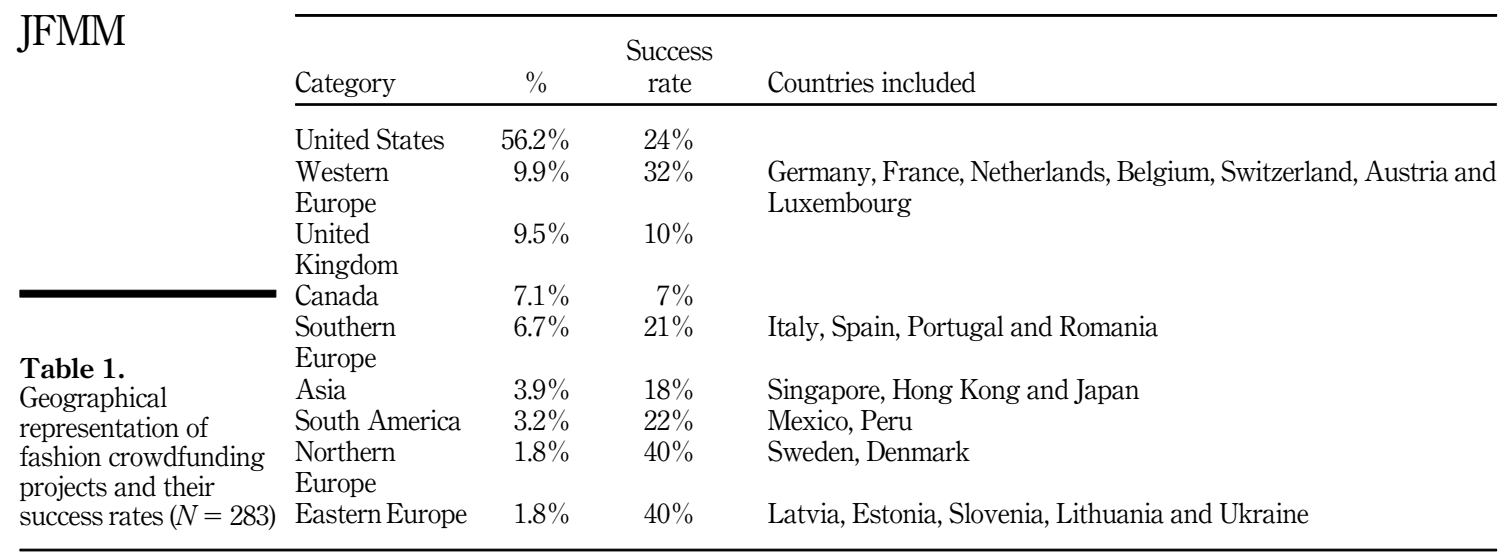

Europe, which had the highest success rates for the fashion crowdfunding campaigns (see Table 1).

The projects were distinguished by campaign founder-assigned classifications. From the most frequent to the most infrequent, they consisted of categories like apparel (t-shirts, denim and casual-wear); accessories (bags, scarves); fashion (anything from fashion-wear, accessories, jewellery etc., but the founder decided to describe it as fashion); jewellery (watches, earrings and bracelets); footwear, ready-to-wear (very similar to apparel); children's wear; couture (very similar to fashion); and pet-fashion. We recoded some of the categories to aid comprehension (see Table 2 below, "Categories explained"). Apparel was the most represented classification, followed by fashion, accessories and pins (typically part of accessories or jewellery). The pin category was by far the most successful at attracting funding ( $65 \%$ success rate), followed by accessories $(40 \%)$. In contrast, the fashion and jewellery classifications were funded less frequently (14 and $13 \%$ success rates, respectively).

We created a separate category for pins as these are qualitatively different from other jewellery products. The standard enamel pins usually have a symbolic meaning, are collectables or use the proceeds for social causes. The highly successful pins are also characterised by low-priced rewards, which makes it distinct from other jewellery products.

To this date, there are not sufficient studies to support a clear reasoning behind specific product patterns within fashion crowdfunding. Nonetheless, it is possible to speculate that accessories present fewer risks in online purchase given that clothing measurements across

Table 2.

Category representation of fashion crowdfunding projects and their success rates $(N=283)$

\begin{tabular}{|c|c|c|c|}
\hline Category & $\%$ & $\begin{array}{c}\text { Success } \\
\text { rate }\end{array}$ & Categories explained \\
\hline Apparel & $41 \%$ & $22 \%$ & Apparel \& ready to wear \\
\hline Fashion & $15 \%$ & $14 \%$ & Fashion and couture \\
\hline Accessories & $14 \%$ & $40 \%$ & Accessories, including wigs, excluding pins \\
\hline Pins & $11 \%$ & $65 \%$ & $\begin{array}{l}\text { Due to prevalence of pins in the sample we created a separate new } \\
\text { category to emphasise its extent }\end{array}$ \\
\hline Jewellery & $8 \%$ & $13 \%$ & Jewellery excluding pins \\
\hline Footwear & $7 \%$ & $20 \%$ & \\
\hline Other & $3 \%$ & $33 \%$ & $\begin{array}{l}\text { Infrequent items such as pet-fashion, children's wear, other miscellaneous } \\
\text { projects such as phone apps, school for girls and home objects (e.g. } \\
\text { pillows) }\end{array}$ \\
\hline
\end{tabular}


countries potentially impact consumption practices and that there are no size adjustments to be made in the case of accessories apparel. As such, we contend that fashion crowdfunding yields conservative responses from consumers who may prefer to reduce the risks of purchasing new clothing via this mean.

The complete data revealed an overall success rate of $27.9 \%$. The average amount raised by the campaign founders of fashion projects was 11,448 EUR, with the most successful asking for less, 6,205 EUR and the least successful for more, 13,452 EUR. The average campaign duration was 36 days, with a range from 10 to 60 days. The founders of the projects provided backers with a choice of an average of seven rewards, with a minimum of one and a maximum of 31 . The price of an average fashion reward was 164 EUR. In terms of the product lifecycle, $70.6 \%$ of the campaigns asked backers to fund a first-time production. A total of $26.2 \%$ of the projects signalled their product to be functionally innovative. $24.5 \%$ signalled environmental. The tables below show the descriptive statistics (Table 3) and the correlation between variables (Table 4).

\subsection{Regression}

The regression results can be found below. In Step 1, the logistic regression model with only control variables explained $19.2 \%$ of the variance in crowdfunding success and was statistically significant: $\chi^{2}(4)=63.714, p<0.001$. In accordance with the broader crowdfunding literature, the model predicted a significant negative effect of the goal amount and a significant positive effect of number of rewards. Unlike the previous literature on fashion campaigns, neither video nor the campaign length mattered in predicting success. In Step 2, both predictor and control variables explained $33.3 \%$ of the variance in crowdfunding success and was statistically significant: $\chi^{2}(9)=110.825, p<0.001$. Step 2 has significantly improved the goodness-of-fit $\left(\mathrm{R}^{2} \Delta=14.1 \%, \chi^{2}(5)=47.111, p=0.000\right)$. The model predicted a significant increase in the odds of success for the first-time production, innovative and environmentally sustainable products of a higher price range $(\phi<0.05)$. No overfitting was detected for both regressions (see Table 5).

\section{Discussion}

In their research, Agrawal et al. (2015) highlighted some of the benefits of crowdfunding as a result of the internet-boosted commercialisation: more effective matching between campaign founders and backers; reduced exposure risk; and lower transaction costs due to a two-sided

\begin{tabular}{|c|c|c|c|c|}
\hline & & Successful $(n=78)$ & Unsuccessful $(n=204)$ & \\
\hline Success & $27.7 \%(44.8)$ & & & \\
\hline Goal (EUR) & $11,448(20,653)$ & $6,205(7.317)$ & $13,452(23,570)$ & \\
\hline LN (Goal) & 8.33(1.52) & $7.81(1.57)$ & $8.54(1.46)$ & \\
\hline Length (days) & 35.9 (11.3) & $34.5(9.9)$ & $36.5(11.7)$ & \\
\hline Rewards (\#) & $7.2(5.17)$ & $10.1(5.96)$ & $6.2(4.37)$ & \\
\hline LN (Rewards) & $6.9(4.25)$ & $9.3(3.94)$ & $6.0(4.01)$ & \\
\hline Video presence $(\%)$ & $59.6 \%(49.2)$ & $61.5 \%(49.0)$ & $58.8 \%(49.3)$ & \\
\hline Lifecycle (\% expansion) & $29.4 \%(45.7)$ & $10.3 \%(30.5)$ & $36.8 \%(48.3)$ & \\
\hline Innovativeness $(\%)$ & $26.2 \%(44.1)$ & $38.5 \%(49)$ & $21.6 \%(41.2)$ & Descriptive statistics of \\
\hline Average reward price (EUR) & $164.02(275.21)$ & $181.71(216.21)$ & $157.26(294.86)$ & the factors affecting \\
\hline LN (Price) & $4.29(1.24)$ & $4.55(1.22)$ & $4.19(1.25)$ & fashion crowdfunding \\
\hline Sustainability Environ. \% & $24.5 \%(43.1)$ & $35.9 \%(48.3)$ & $20.1 \%(40.2)$ & campaigns (Mean \\
\hline Sustainability social $\%$ & $30.1 \%(46.0)$ & $37.2 \%(48.6)$ & $27.5 \%(44.7)$ & $(\mathrm{SD}) ; N=283)$ \\
\hline
\end{tabular}


JFMM

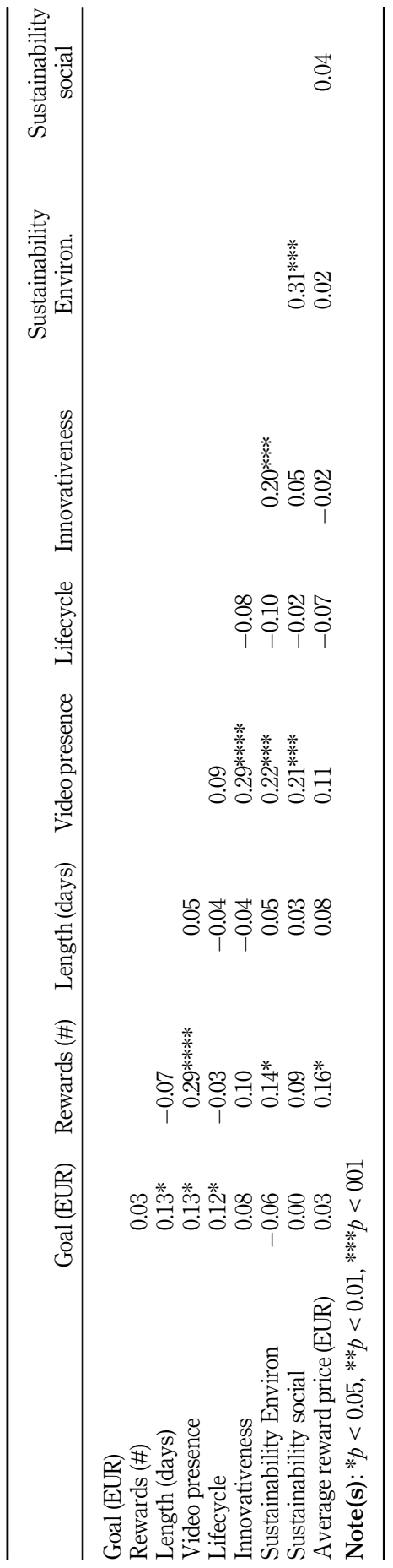

Table 4. 
market structure (see Rochet and Tirole, 2003). As we discussed before, crowdfunding allows entrepreneurs to engage with backers and to confirm the extent to which they support new creative ideas (Stanko and Henard, 2016). Within the realm of fashion products, innovative ideas may also imply the presence of SS and ES (Calic and Mosakowski, 2016). Moreover, when prices are high, the distinctive features of goods matter become important due to social signalling that is prevalent in crowdfunding settings. In our analysis, we learnt that lifecycle, innovativeness, price and ES features of fashion projects - all contribute to the success of crowdfunding campaigns, while SS does not show significance. What is more, in our analyses the chosen predictors of sustainability, price, innovativeness and lifecycle explain almost as much variance as other more typically researched indicators, namely goal and length of the campaign (Butticè and Unghetto, 2021).

\subsection{Innovativeness}

The strongest predictor of fashion crowdfunding success was the functional innovativeness of the projects, even though it was not a common feature. This observation can be interpreted as the outcome of Kickstarter's mission of supporting innovative ideas. While backers have other possible sources of finding new fashion items, Kickstarter advocates for creativity and is perceived by the media as a platform driven by innovation. Hence, it is not surprising that the projects attracting the most funding are also innovative. The fact that the fashion projects' success was so strongly associated with innovative features might also explain why fashion as a category is often underfunded. If innovation is the largest contributory factor in fashion crowdfunding success, it is unsurprising that only $27 \%$ of these campaigns are funded, given that only $25 \%$ of them were coded as innovative. Nevertheless, it may be challenging for fashion designers (and might not be the main purpose) to come up functional innovations for a product that is mainly characterised by style and aesthetics. Indeed, the functional purpose of a fashion product is usually simple, especially for the apparel and fashion categories. This may also explain why accessories have a much higher success rate (i.e. glasses, bags, watches, etc.).

\subsection{Sustainability}

Our study identified that sustainable projects attract more funding. However, most of this success was driven by ES rather than social. In fashion crowdfunding, therefore, environmental discourse within the project matters more than socially responsible. We

\begin{tabular}{|c|c|c|c|}
\hline Variable & Model 1 & Model 2 & \\
\hline \multicolumn{4}{|l|}{ Predictor Variables } \\
\hline Lifecycle (dummy) $_{\text {(dum }}$ & & $0.209 * *$ & \\
\hline Innovativeness (dummy) & & $5.216^{* * * *}$ & \\
\hline Price (ln) (EUR) & & $1.391 * *$ & \\
\hline Sustainability Environ. (dummy) & & $2.533^{*}$ & \\
\hline Sustainability social (dummy) & & 1.798 & \\
\hline \multicolumn{3}{|l|}{ Control Variables } & Table 5. \\
\hline Goal (ln) (EUR) & $0.541 * * *$ & $0.376^{* * * *}$ & Model summaries of \\
\hline Length (days) & 1.000 & 0.999 & binomial logistic \\
\hline Rewards $(\ln )_{\text {capped }}(\#)$ & $1.283^{* * *}$ & $1.318^{* * *}$ & regression assessing \\
\hline Video presence (dummy) & 1.315 & 0.925 & success factors in \\
\hline McFadden Pseudo- $\mathrm{R}^{2}$ & 0.192 & 0.333 & $\begin{array}{l}\text { crowdfunding } \\
\text { campaigns (Odds }\end{array}$ \\
\hline \multicolumn{3}{|l|}{$\operatorname{Note}(\mathbf{s}):{ }^{*} p<0.05,{ }^{* *} p<0.01,{ }^{* * *} p<0.001$} & $\operatorname{ratios} ; N=283$ ) \\
\hline
\end{tabular}

When fashion meets crowdfunding

\section{西}


speculate that this might happen due to the pressing concerns related to environmentalism and climate change as well as its associations with fashion industry - an industry that is widely considered polluting. Additionally, for the upcoming designers the lower social impact of their projects might already be assumed, and additional signalling is futile. On the other hand, environmentally conscious purchases make it achievable for consumers to signal a need for change in fashion industry or possibly even the crowdfunding platforms are amongst the few places where environmentally sustainable fashion items can be purchased.

\subsection{Price}

A higher price range of rewards was shown to positively affect crowdfunding success. As mentioned in the literature review, a higher price of an item may signal quality, prestige and exclusivity, which is rewarded by backers. It is also logical that a product that is durable, innovative and socially sustainable would cost more. As such, while lower funding goals are preferred and signal the feasibility of a project, a higher average price of rewards might indicate that a project is worth backing. Higher price could also send signals of higher quality as it is often the case in other fashion ventures (see "Veblen goods"). In this situation, online fashion crowdfunding is similar to the offline fashion consumption where buyers prefer exclusive and expensive items compared to mass-produced large retailer goods. In addition, we posit that high prices can signal superior quality, including ES and innovativeness described above.

\subsection{Lifecycle}

As a funding scheme for new entrepreneurial ventures that also allows for market testing, crowdfunding is important for newcomers and their early-stage products that otherwise would potentially have limited means of access to funding. As long as fashion crowdfunding does not pertain to large conglomerates or mass production, crowdfunding offers promising routes for independent designers, solo creators and small companies in this industry. This helps to reduce the power of established market structures and traditional gatekeeping in fashion industries. With the rise of new fashion schools and public knowledge about fashion (Wubs et al., 2020b), it is likely that crowdfunding will be utilised by the creators who otherwise would have limited access to investors (e.g. business angels, venture capital firms and loans from banks). We observed that backers on Kickstarter show more support for the early-stage production, with early-stage projects having greater odds of success. This entails that creators may benefit from early-stage production and market testing initially, but further stages of production might need to be financed elsewhere.

Finally, another noteworthy observation is that, although the geographical representation of fashion crowdfunding campaigns is consistent with the reports by the European Commission and the Cambridge Centre for Alternative Finances (De Voldere and Zeqo, 2017; Ziegler et al., 2021), showing that crowdfunding is more extensive in Europe and North America (especially for cultural and creative campaigns), and that other markets such as South America are forthcoming, fashion campaigns enjoy higher success rates in Northern, Western and Eastern Europe. This observation, while out of scope for this study, might be an interesting avenue for future research.

\section{Conclusion}

Our hypotheses have enquired about the odds of success for fashion crowdfunding project. Namely, we looked at the effect of projects' social and ES, innovation, price levels of rewards and stage of production. We learnt that innovative and environmentally sustainable fashion projects with higher priced rewards and at the early stage of production enjoy greater rates of 
success on Kickstarter. Via a number of signals displayed online crowdfunding helps backers to reduce their search costs and creators to discover the preferences of potential consumers. In this study, we can trace the presence of low risk/high trust relationships within the successful crowdfunding campaigns, and further understand fashion as a good with reputational characteristics. Garments actively represent identities, ideologies and societal views. Consistent with crowdfunding literature, partaking in crowdfunding projects often represents participation in a community, sharing ideas and signalling the need for change by supporting environmentalism and small scale production.

Therefore, projects with lower goals but higher priced rewards, indicating being achievable but also showing quality, ES and innovation attract the most backers on crowdfunding platforms. Our results have pointed out that environmentally-focussed products yield better results than products with socially driven narratives. This, of course, is a comparative device to test which form of sustainability is more supported. In other sectors socially-driven projects yield better success levels, but fashion shows greater preference towards environmentalism. Our study also shows that higher prices (expressed in the reward options) yield better results, which confirms that fashion consumption is often motivated by distinction which is assessed via price. We cannot, however, determine if this observation would vary according to a specific demographic of supporters. This question remains an avenue for future research.

We also learnt that early-stage entrepreneurs seem to achieve greater success, which relates to crowdfunding being an innovative channel for novel creators, new products and ideas that emerge in the "long-tail" (Anderson, 2006). Lastly, we confirm the relevance of innovative narratives within the scope of crowdfunding campaigns. As discussed before, a suggestion for further studies is to delve into the perception of consumers about innovation, as the majority of success-factors studies are based on the unidimensional signalling features of online campaigns.

A limitation of this study is its reliance on a project's narratives, meaning that we do not address directly the perceptions of consumers concerning innovation, sustainability or stage of production. This could be developed further in forthcoming studies. Moreover, a replication study using a larger sample (or, even better, a big-data analysis) to test our results would be valuable. Other platforms (including international versions) should also be examined to assess whether the results translate cross-culturally.

Finally, the academic relevance of this study towards the advancement of crowdfunding research and other alternative funding schemes within specific sectors and domains is clear. To our understanding, the current crowdfunding literature has sufficiently evolved to allow for sector-specific discussions. More specifically, when it comes to fashion, it is vital to assess the importance of sustainability in campaign discourses as, on one hand, crowdfunding claims to be innovative through product development, and, secondly, fashion is remarkably a sector pressured to implement changes in its production process. As such, we believe that this study has important contributions to practitioners willing to undertake an alternative funding path that might prove to be rewarding for creators willing to foster engagement, attention and a more sustainable business model.

\section{Notes}

1. Approximately $26 \%$ of fashion-related projects on Kickstarter had funding success (Kickstarter, 2021).

2. The US-based platform Kickstarter (2021) typically accepts projects from all the cultural and creative industries, as long as they comply with legal regulations. In 2018 , fashion campaigns had a success rate of $27 \%$, one of the lowest on the site. This platform also reinforces the value of innovation on its website by providing access to innovation-hungry consumers or early-adopters.

When fashion meets crowdfunding 
3. Furthermore, Paschen (2017) excludes the pre-purchase model, which represents a large portion of all the funds collected in crowdfunding campaigns (Rossi, 2014).

4. For example, the \#WhoMadeMyClothes campaign initiated by the non-profit organisation Fashion Revolution.

5. A complementary perspective is given by Vismara (2018) in the case of equity crowdfunding. He finds that sustainable orientation does not bring more funds, but it does bring more qualified funders (called "restricted investors"). These investors follow "community logic" in that their support is conditioned by a sense of long-term contribution to either preservation or social environments.

6. This is due to loan-based projects their work in underprivileged places. As many loan projects are created by local farmers, craftsmen and artisans, backers expect their contribution to be used sustainably in exchange for not having pecuniary rewards off their temporary loans.

7. In crowdfunding campaigns, each reward is offered by a given price. On average, all rewards and their prices combined should depict the overall price of the products (rewards) offered in any campaign.

8. Regarding the timeframe of our dataset, we reinforce that, usually, the success rates of crowdfunding calls do not vary substantially, especially within cultural sectors. Fashion remains with an intermediary success rate on Kickstarter (2020).

9. $0.98,0.99,0.98,0.99,0.98$ and 0.98 , respectively.

\section{References}

Abernathy, W.J. and Clark, K.B. (1985), "Innovation: mapping the winds of creative destruction", Research Policy, Vol. 14 No. 1, pp. 3-22.

Agrawal, A.K., Catalini, C. and Goldfarb, A. (2015), "Crowdfunding: geography, social networks, and the timing of investment decisions", Journal of Economics \& Management Strategy, Vol. 24, pp. 253-274.

Akerlof, G.A. (1970), “The market for "lemons": quality uncertainty and the market mechanism”, The Quarterly Journal of Economics, Vol. 84 No. 3, pp. 488-500.

Anderson, C. (2006), The Long Tail: Why the Future of Business Is Selling Less of More, Hyperion, New York.

Andreoni, J. (1990), "Impure altruism and donations to public goods: a theory of warm-glow giving", The Economic Journal, Vol. 100 No. 401, pp. 464-477.

Andreozzi, L. and Bianchi, M. (2007), "Fashion: why people like it and theorists do not", in Bianchi, M. (Ed.), The Evolution of Consumption: Theories and Practices, Emerald Group Publishing Limited, Bingley, UK, pp. 209-229.

Anzilotti, E. (2018), "This leather is made from mushrooms, not cows", Fastcompany, 24 April, available at: https://www.fastcompany.com/40562633/this-leather-is-made-from-mushroomsnot-cows (accessed 15 January 2021).

Aspers, P. and Godart, F. (2013), "Sociology of fashion: order and change", Annual Review of Sociology, Vol. 39, pp. 171-192.

Beard, N.D. (2008), "The branding of ethical fashion and the consumer: a luxury niche or mass- market reality?", Fashion Theory, Vol. 12 No. 4, pp. 447-467.

Beier, M. and Wagner, K. (2015), "Crowdfunding success: a perspective from social media and E-commerce", AISeL Proceedings, available at: https:/www.researchgate.net/publication/ 286779944_Crowdfunding_Success_A_Perspective_from_Social_Media_and_E-Commerce (accessed 12 December 2020).

Belleflamme, P., Lambert, T. and Schwienbacher, A. (2014), "Crowdfunding: tapping the right crowd”, Journal of Business Venturing, Vol. 29, pp. 585-609. 
Bhardwaj, V. and Fairhurst, A. (2010), "Fast fashion: response to changes in the fashion industry", The International Review of Retail, Distribution and Consumer Research, Vol. 20 No. 1, pp. 165-173.

Bowerman, B.L. and O'Connell, R.T. (1990), Linear Statistical Models: An Applied Approach, 2nd ed., Duxbury, Belmont, CA.

Bretschneider, U., Knaub, K. and Wieck, E. (2014), "Motivations for crowdfunding: what drives the crowd to invest in start-ups?", AISeL Proceedings, available at: https://aisel.aisnet.org/ecis2014/ proceedings/track05/6/ (accessed 12 December 2020).

Brydges, T. (2018), "Made in Canada: local production networks in the Canadian fashion industry", The Canadian Geographer/Le Géographe canadien, Vol. 62 No. 2, pp. 238-249.

Brydges, T., Lavanga, M. and von Gunten, L. (2014), "Entrepreneurship in the fashion industry: a case study of slow fashion businesses", in Schramme, A., Hagoort, G. and Kooyman, R. (Eds), Beyond Frames. Dynamics between the Creative Industries, Knowledge Institutions and the Urban Context, Eburon Academic Press/University of Chicago Press, Delft, pp. 73-79.

Brydges, T., Hracs, B.J. and Lavanga, M. (2018), "Evolution versus entrenchment: debating the impact of digitization, democratization and diffusion in the global fashion industry", International Journal of Fashion Studies, Vol. 5 No. 2, pp. 365-372.

Butticè, V. and Ughetto, E. (2021), "What, where, who, and how? A bibliometric study of crowdfunding research", IEEE Transactions on Engineering Management, pp. 1-22.

Calic, G. and Mosakowski, E. (2016), "Kicking off social entrepreneurship: how A sustainability orientation influences crowdfunding success", Journal of Management Studies, Vol. 53 No. 5 , pp. 738-767.

Caves, R. (2000), Creative Industries: Contracts between Arts and Commerce, Harvard University Press, Cambridge, MA.

Chan, C.R. and Parhankangas, A. (2017), "Crowdfunding innovative ideas: how incremental and radical innovativeness influence funding outcomes", Entrepreneurship Theory and Practice, Vol. 41 No. 2, pp. 237-263.

Chapman, J.A. (2015), Emotionally Durable Design: Objects, Experiences and Empathy, 2nd ed., Routledge, London.

Christopher, M., Lowson, R. and Peck, H. (2004), "Creating agile supply chains in the fashion Industry", International Journal of Retail \& Distribution Management, Vol. 32 No. 8, pp. 367-376.

Clark, H. (2008), "Slow + fashion: an oxymoron—or a promise for the future...?", Fashion Theory, Vol. 12 No. 4, pp. 427-446.

Colombo, M.G., Franzoni, C. and Rossi-Lamastra, C. (2015), "Internal social capital and the attraction of early contributions in crowdfunding", Entrepreneurship Theory and Practice, Vol. 39 No. 1, pp. $75-100$.

Courtney, C., Dutta, S. and Li, Y. (2016), "Resolving information asymmetry: signaling, endorsement, and crowdfunding success", Entrepreneurship Theory and Practice, Vol. 41 No. 2, pp. 265-290.

Crane, D. (1997), "Globalization, organizational size, and innovation in the French luxury fashion industry: production of culture theory revisited", Poetics, Vol. 24 No. 6, pp. 393-414, ISSN 0304-422X, doi: 10.1016/S0304-422X(97)00004-1.

Crewe, L. (2013), "Tailoring and tweed: mapping the spaces of slow fashion”, in Bruzzi, S. and Church Gibson, P. (Eds), Fashion Cultures: Theories, Explorations and Analysis, Routledge, London, pp. 200-214.

Cumming, D. and Hornuf, L. (Eds), (2018), in The Economics of Crowdfunding, Palgrave Macmillan, UK.

Czarniawska, B. (2011), "Introduction to the special themed section: fashion in research and in management”, Organization Studies, Vol. 32 No. 5, pp. 599-602.

Dalla Chiesa, C. (2021), "The artists' critique on crowdfunding and online gift-giving”, The Journal of Arts Management, Law, and Society, Vol. 52 No. 1, pp. 20-36, doi: 10.1080/10632921.2021. 1997848. 
Dalla Chiesa, C.D. and Handke, C. (2020), "Crowdfunding", in Towse, R. and Navarrette-Hernandez, T. (Eds), Handbook of Cultural Economics, 3rd ed., Edward Elgar, London, pp. 158-167.

De Voldere, I. and Zeqo, K. (2017), Crowdfunding. Reshaping the Crowd's Engagement in Culture, European Commission, Brussels, available at: https://europa.eu/capacity4dev/crowdfunding/ documents/new-report-crowdfunding-reshaping-crowds-engagement-culture (accessed 15 September 2020).

Dey, S., Duff, B.R.L., Karahalios, K. and Fu, W. (2017), "The art and science of persuasion: not all crowdfunding campaign videos are the same", Proceedings of the 2017 ACM Conference on Computer Supported Cooperative Work and Social Computing, ACM, pp. 755-769.

Dickinson, V. (2011), "Cash flow patterns as a proxy for firm life cycle", The Accounting Review, Vol. 86 No. 6, pp. 1969-1994.

Downes, L. (2013), “Crowdfunding's big-bang moment”, Harvard Business Review, available at: https:// hbr.org/2013/10/crowdfundings-big-bang-moment (accessed 12 September 2020).

Fagerberg, J. (2004), What Do We Know about Innovation? Lessons from the TEARI Project, TEARI project. Report No. 1 (2nd Draft, September 20, 2004), Centre for Technology, Innovation and Culture, University of Oslo, available at: https://core.ac.uk/download/pdf/6484411.pdf (accessed 20 November 2021).

Field, A. (2013), Discovering Statistics Using IBM SPSS Statistics, Sage, London.

Fletcher, K. (2012), "Durability, fashion, sustainability: the processes and practices of use", Fashion Practice, Vol. 4 No. 2, pp. 221-238.

Fletcher, K. and Grose, L. (2012), Fashion \& Sustainability: Design for Change, Laurence King Publishing, London.

Frey, B. (1994), "How intrinsic motivation is crowded out and in", Rationality and Society, Vol. 6 No. 3 , pp. 334-352.

Gafni, H., Marom, D. and Sade, O. (2019), "Are the life and death of an early-stage venture indeed in the power of the tongue? Lessons from online crowdfunding pitches", Strategy Entrepreneurship Journal, Vol. 13 No. 1, pp. 3-23.

Gerber, E.M. and Hui, J. (2016), "Crowdfunding: how and why people participate", in Méric, J., Maque, I. and Brabet, J. (Eds), International Perspectives on Crowdfunding: Positive, Normative and Critical Theory, Emerald Insight, UK, pp. 37-64.

Gorbatai, A. and Nelson, L. (2015), "Gender and the language of crowdfunding", Academy of Management Proceedings, Vol. 1, pp. 15785-15785.

Gwilt, A., Payne, A. and Ruthschilling, E.A. (Eds) (2019), Global Perspectives on Sustainable Fashion, Bloomsbury Academic Publishers, London.

Hemphill, C. and Suk, J. (2009), "The law, culture, and economics of fashion”, Stanford Law Review, Vol. 61, pp. 101-151.

Hobbs, J., Grigore, G. and Molesworth, M. (2016), "Success in the management of crowdfunding projects in the creative industries", Internet Research, Vol. 26 No. 1, pp. 146-166.

Hoffman, J. and Lecamp, L. (2015), Independent Luxury: The Four Innovation Strategies to Endure in the Consolidation Jungle, Palgrave Macmillan, UK.

Jacobs, S., Cambre, B., Huysentruyt, M. and Schramme, A. (2016), "Unraveling Belgian fashion Designers high perceived success: a set-theoretic approach”, Journal of Business Research, Vol. 69 No. 4, pp. 1407-1411.

Janssens, A. and Lavanga, M. (2020), "An expensive, confusing, and ineffective suit of armor: investigating risks of design piracy and perceptions of the design rights available to emerging fashion designers in the digital age", Fashion Theory, Vol. 24 No. 2, pp. 229-260.

Kapferer, J.N. and Bastien, V. (2012), The Luxury Strategy: Break the Rules of Marketing to Build Luxury Brands, Kogan Page Publishers, London. 
Kickstarter (2020), Kickstarter Stats, Kickstarter, available at: https:/www.kickstarter.com/help/stats? ref=hello (accessed 15 October 2020).

Kickstarter (2021), available at: www.kickstarter.com.

Kirmani, A. and Rao, R. (2000), "No pain, no gain: a critical review of the literature on signalling unobservable product quality”, Journal of Marketing, Vol. 64 No. 2, pp. 66-79.

Kretschmer, M., Klimis, G.M. and Choi, C.J. (1999), "Increasing returns and social contagion in cultural industries”, British Journal of Management, Vol. 10, pp. 61-72.

Kuppuswamy, V. and Bayus, B.L. (2015), Crowdfunding Creative Ideas: The Dynamics of Project Backers in Kickstarter, Research Paper, UNC Kenan-Flagler. doi: 10.2139/ssrn.2234765.

Kuti, M. and Madarász, G. (2014), “Crowdfunding”, Public Finance Quarterly (0031-496X), Vol. 59 No. 3, pp. 366-355.

Lasrado, L.A. (2013), Crowd Funding in Finland-a New Alternative Disruptive Funding Instrument for Businesses, Master of Science Thesis, Tampere University of Technology, available at: https://dspace.cc.tut.fi/dpub/bitstream/handle/123456789/21784/Lasrado.pdf?sequence $=3$ (accessed 15 September 2020).

Lavanga, M. (2018), "The role of the Pitti Uomo trade fair in the menswear fashion industry", in Blaszczyk, R. and Wubs, B. (Eds), The Fashion Forecasters: A Hidden History of Color and Trend Prediction, Bloomsbury Academic Publishing, London, pp. 191-209.

Lavanga, M. (2019), “A spotlight on: sustainable fashion in The Netherlands”, in Gwilt, A., Payne, A. and Ruthschilling, E.A. (Eds), Global Perspectives on Sustainable Fashion, Bloomsbury Academic Publishers, London, pp. 97-99.

Leboeuf, G. and Schwienbacher, A. (2008), "Crowdfunding as a new financing tool", in Cumming, D. and Hornuf, L. (Eds), The Economics of Crowdfunding: Startups, Portals and Investor Behavior, Springer Publishing, NY, pp. 11-28.

Lee, N., Sameen, H. and Cowling, M. (2015), “Access to finance for innovative SMEs since the financial crisis”, Research Policy, Vol. 44, pp. 370-380.

Leslie, D., Brail, S. and Hunt, M. (2014), “Crafting an antidote to fast fashion: the case of Toronto's independent fashion design sector", Growth and Change, Vol. 45 No. 2, pp. 222-239.

Mæhle, N. (2020), "Sustainable crowdfunding: insights from the project perspective", Baltic Journal of Management, Vol. 15 No. 2, pp. 281-302.

Manning, S. and Bejarano, T.A. (2017), "Convincing the crowd: entrepreneurial storytelling in crowdfunding campaigns”, Strategic Organization, Vol. 15 No. 2, pp. 194-219.

Maza, S. (2006), "Luxury, morality, and social change", in Kates, G. (Ed.), The French Revolution. Recent Debates and New Controversies, 2nd ed., Routledge, New York, pp. 113-131.

Mendes Da Silva, W., Rossoni, L., Conte, B.S., Gattaz, C. and Francisco, E.R. (2016), "The impacts of fundraising periods and geographic distance on financing music production via crowdfunding in Brazil", Journal of Cultural Economics, Vol. 40, pp. 75-99.

Mollick, E. (2014), "The dynamics of crowdfunding: determinants of success and failure", Journal of Business Venturing, Vol. 29, pp. 1-16.

Mollick, E. and Robb, A. (2016), "Democratizing innovation and capital access: the role of crowdfunding”, California Management Review, Vol. 58, pp. 72-87.

Motylska-Kuzma, A. (2018), "Crowdfunding and sustainable development", Sustainability, Vol. 10 No. 12, 4650, doi: 10.3390/su10124650.

Myers, R. (1990), Classical and Modern Regression with Applications, 2nd ed., Duxbury, Boston, MA.

Ordanini, A., Miceli, L., Pizzetti, M. and Parasuraman, A. (2011), "Crowd-funding: transforming customers into investors through innovative service platforms", Journal of Service Management, Vol. 22 No. 4, pp. 443-470.
When fashion meets crowdfunding 
Park, H.-J., Rabolt, N.J. and Jeon, K.S. (2008), "Purchasing global luxury brands among young. Korean consumers", Journal of Fashion Marketing and Management, Vol. 12 No. 2, pp. 244-259.

Paschen, J. (2017), "Choose wisely: crowdfunding through the stages of the start-up life cycle", Business Horizons, Vol. 60 No. 2, pp. 179-188.

Peduzzi, P., Concato, J., Kemper, E., Holford, T.R. and Feinstein, A.R. (1996), "A simulation study of the number of events per variable in logistic regression analysis", Journal of clinical Epidemiology, Vol. 49 No. 12, pp. 1373-1379.

Pratt, A., Borrione, P., Lavanga, M. and D’Ovidio, M. (2012), "International change and technological evolution in the fashion industry", in Agnoletti, M., Carandini, A. and Santagata, W. (Eds), Essays and Researches. International Biennial of Cultural and Environmental Heritage, Bandecchi \& Vivaldi Editori e Stampatori, Pontedera, pp. 359-376.

R Core Team (2013), R: A Language and Environment for Statistical Computing, R Foundation for Statistical Computing, Vienna, Austria, available at: https://www.r-project.org/ (accessed 1 September 2020).

Raustiala, K. and Sprigman, C. (2006), "The piracy paradox: innovation and intellectual property in fashion design”, Virginia Law Review, Vol. 92 No. 8, pp. 1687-1777.

Reinach, S. (2005), "China and Italy: fast fashion versus Prêt à Porter-towards a new culture of fashion", Fashion Theory, Vol. 9 No. 1, pp. 43-56.

Robertson, M. (2021), Sustainability Principles and Practice, 3rd ed., Routledge, London.

Robinson, D.E. (1958), "Fashion theory and product design", Harvard Business Review, Vol. 36 No. 6, pp. 126-138.

Robinson, D.E. (1961), "The economics of fashion demand", Quarterly Journal of Economics, Vol. 75, pp. 376-398.

Rochet, J.-C. and Tirole, J. (2003), "Platform competition in two-sided markets", Journal of the European Economic Association, Vol. 1, pp. 990-1029.

Rossi, M. (2014), "The new ways to raise capital: an exploratory study of crowdfunding", International Journal of Financial Research, Vol. 5 No. 2, pp. 8-18.

Santagata, W. (2004), "Creativity, fashion and market behavior", in Power, D. and Scott, A. (Eds), Cultural Industries and the Production of Culture, Routledge, London, pp. 87-101.

Schwienbacher, A. and Larralde, B. (2010), "Crowdfunding of small entrepreneurial ventures", in Cumming, D. (Ed.), The Oxford Handbook of Entrepreneurial Finance, Oxford University Press, Oxford, pp. 369-392.

SDG (2021), "Sustainable development goals knowledge platform", available at: https:// sustainabledevelopment.un.org/topics/sustainabledevelopmentgoals (accessed 30 November 2021).

Sharp, A.M., Liu, Y.C. and Mai, W.Y.C.C. (2014), "Crowdfunding success factors", International Research Journal of Applied Finance, Vol. 7, pp. 822-832.

Shneor, R. and Vik, A.A. (2020), "Crowdfunding success: a systematic literature review 2010-2017", Baltic Journal of Management, Vol. 15 No. 2.

Short, J.C., Ketchen, D.J., McKenny, A.F., Allison, T.H. and Ireland, R.D. (2017), "Research on crowdfunding: reviewing the (very recent) past and celebrating the present", Entrepreneurship Theory and Practice, Vol. 41 No. 2, pp. 149-160.

Sorenson, O., Assenova, V., Li, G., Boada, J. and Fleming, L. (2016), "Expand innovation finance via crowdfunding", Science, Vol. 354, pp. 1526-1528.

Sproles, G.B. (1974), "Fashion theory: a conceptual framework", in Ward, S. and Wright, P. (Eds), NA Advances in Consumer Research, Association for Consumer Research, Ann Abor, MI, Vol. 01, pp. $463-472$. 
Sproles, G.B. (1981), “Analyzing fashion life cycles: principles and perspectives”, Journal of Marketing, Vol. 45, pp. 116-124.

Stanko, M.A. and Henard, D.H. (2016), "How crowdfunding influences innovation", MIT Sloan Management Review, Vol. 57 No. 3, pp. 14-17.

Tidd, J., Bessant, J. and Pavitt, K. (Eds), (2011), Managing Innovation: Integrating Technological, Market and Organizational Change, 3rd ed., Wiley, NY.

Todeschini, B.V., Cortimiglia, M.N., Callegaro-de-Menezes, D. and Ghezzi, A. (2017), "Innovative and sustainable business models in the fashion industry: entrepreneurial drivers, opportunities, and challenges", Business Horizons, Vol. 60 No. 6, pp. 759-770.

Tukey, J.W. (1977), Exploratory Data Analysis, Addison-Wesley, Boston, MA.

Veblen, T. and Chase, S. (1934), The Theory of the Leisure Class: An Economic Study of Institutions, Modern Library, New York.

Viotto da Cruz, J. (2018), "Beyond financing: crowdfunding as an informational mechanism”, Journal of Business Venturing, Vol. 33, pp. 371-393.

Vismara, S. (2018), "Signalling to overcome inefficiencies in crowdfunding markets", in Cumming, D. and Hornuf, L. (Eds), The Economics of Crowdfunding, Palgrave Macmillan, UK, pp. 29-56.

Vismara, S. (2019), "Sustainability in equity crowdfunding", Technological Forecasting and Social Change, Vol. 141, pp. 98-106, doi: 10.1016/j.techfore.2018.07.014.

Watercutter, A. (2013), "Why people get annoyed at celebrities on Kickstarter (and why they probably shouldn't)", Wired, 30 April 2013, available at: https://www.wired.com/2013/04/zach-braffkickstarter/.

Wehnert, P., Baccarella, C.V. and Beckmann, M. (2019), "In crowdfunding we trust? Investigating crowdfunding success as a signal for enhancing trust in sustainable product features", Technological Forecasting and Social Change, Vol. 141, pp. 128-137.

Wubs, B., Lavanga, M. and Janssens, A. (2020a), "Letter from the editors: the past and present of fashion cities", Fashion Theory, Vol. 24 No. 3, pp. 319-324.

Wubs, B., Lavanga, M., Darpy, D., Depeyre, C., Segreto, L. and Popowska, M. (2020b), RE-FRAME FASHION Report: Innovation in Fashion Education, REFRAME FASHION Publications (Erasmus+ Strategic Partnerships for Higher Education Programme of the European Union), Rotterdam, Paris, Gdańsk, available at: https://repub.eur.nl/pub/135348 (accessed 4 August 2021).

Ziegler, T., Shneor, R., Wenzlaff, K., Wenzlaff, K., Suresh, K., Paes, F., Mammadova, M., Wanga, C., Kekre, N., Mutinda, S., Wanxin Wang, B., Closs, C.L., Zhang, B., Forbes, H., Soki, E., Alam, N. and Knaup, C. (2021), "The $2^{\text {nd }}$ global alternative finance market benchmarking report", Report from the Cambridge Center for Alternative Finance, Cambridge, UK, available at: https://www. jbs.cam.ac.uk/faculty-research/centres/alternative-finance/publications/the-2nd-global-\% 20alternative-finance-market-benchmarking-report/ (accessed 4 August 2021).

\section{Corresponding author}

Carolina Dalla Chiesa can be contacted at: dallachiesa@eshcc.eur.nl

For instructions on how to order reprints of this article, please visit our website:

www.emeraldgrouppublishing.com/licensing/reprints.htm

Or contact us for further details: permissions@emeraldinsight.com 